\title{
Akıllı Şebekeler İçin Elektriksel Güç Harcama Verilerinin İnternet Üzerinden Takibini Sağlayan Kablosuz Güç Ölçüm Sistemi
}

\author{
İsmail DERELI ${ }^{1 *}$, İsmail TEMİZ² \\ ${ }^{1}$ Marmara Üniversitesi, Fen Bilimleri Enstitüsü, İstanbul, Türkiye \\ ${ }^{2}$ Marmara Üniversitesi, Teknoloji Fakültesi, Mekatronik Mühendisliği, İstanbul, Türkiye
}

Geliş / Received: 03/03/2019, Kabul / Accepted: 15/12/2019

\begin{abstract}
$\ddot{O} \mathbf{z}$
Artan nüfus ve buna bağlı olarak artan enerji tüketimi, kaynakların etkin olarak kullanılması zorunluluğunu ortaya çıkarmaktadır. Bu kaynak türlerinden önemli bir tanesi elektrik enerjisi olmaktadır. Çalışmamızda, elektrik enerjisi tüketiminin etkin bir şekilde kontrol edilebilmesi için kullanıcıların, harcadıkları enerji miktarlarını anlık olarak takip edebileceği bir sistemin tasarımı gerçekleştirilmiştir. Sistemi oluşturan farklı yapı mimarileri ile uygun bir veri iletim yöntemi oluşturulmuş, komponentlerin yapı içerisindeki davranışları ve kullanım yöntemleri incelenmiştir. Oluşturulan sistem sayesinde kişi veya kurumların, harcadıkları elektriksel güç değerlerini denetleyebilmeleri ve bu yönde planlama yapabilmeleri sağlanarak, kullanılan makine ve cihazların uygun zaman aralıklarında çalıştırılması gerçekleştirilebilecektir.
\end{abstract}

Anahtar Kelimeler: Enerji Yönetimi, Kablosuz Sensör Ağları, CS5490 Entegresi, PHP-MySQL, Zigbee Haberleşme Protokolü.

\section{Wireless Power Measurement System To Monitor Electrical Power Consumption Datas Over The Internet for Smart Grid}

\begin{abstract}
Increasing population and consequently increasing energy consumption reveal the necessity of efficient use of resources. One of these types of sources is electrical energy. In our study, a system has been designed in which users can follow the instant amount of energy that they spend in order to effectively control electricity consumption. An appropriate data transmission method was formed with the different building architectures that form the system and the behaviors and usage methods of the components within the structure were examined. Thanks to the created system, people or instituions will be able to check the electrical power values that they have spent and make planning in this direction, and using machines and devices that are used will be able to get operated at appropriate time intervals.
\end{abstract}

Keywords: Energy Management, Wireless Sensor Networks, CS5490 IC, PHP-MySQL, Zigbee Communication Protocol.

* Sorumlu Yazar: idereli26@hotmail.com 


\section{Giriş}

Dünya nüfusunun artması, fosil yakıta dayalı enerji rezervlerinin azalması, teknolojik ve sosyal gelişim sonucunda bireyin gündelik yaşamında enerjiye olan bağımlılığının artması, yoğun sanayileşmenin ve verimsiz enerji tüketiminin çevresel etkilerinin görülmeye başlaması gibi etmenler, akıllı enerji yönetimini gündeme getirmiştir. Enerjinin üretim aşamasından başlayarak, iletim, dağıtım ve tüketime kadar uzanan bütün süreçleri kapsayan elektrik şebekesinin, gelişen teknolojik imkânlar ile daha verimli, daha güvenli, daha çevre dostu ve daha yönetilebilir kılınması çabaları akıllı şebeke kavramını doğurmuştur (Akçin vd., 2013).

Akıllı şebekenin başlıca üstünlüklerini şu şekilde sıralayabiliriz;

- Tüketicilere daha kapsamlı bilgi ve enerji tüketim tarifeleri sunabilir.

- Ak1llı ev otomasyon projelerinin hayata geçirilebilmesine olanak sağlayarak tüketicinin elektrik sistemindeki optimizasyonunda kendi rollerini oynama imkânı tanınabilir.

- Dağıtım sisteminde ve son kullanıcı bağlantılarında mikro üretimin eklenmesi ile şebekedeki güç kalitesi optimize edilebilir.

- Elektrik tüketim oranları belirli noktalarda gerçek zamanlı olarak karşılaştırılarak elektrik kayıp-kaçak oranı azaltılabilir.

- Sistemin ihtiyaç duyacağ yatırımları, elde edilen ölçümler ve analizler sayesinde daha iyi planlanabilir (Akcanca vd., 2011).

- Verilerin takip yöntemlerinin optimizasyonu ile kullanicilar arasında enerji paylaşım yöntemleri oluşturulabilir (Zafar vd., 2018).

Ak1llı elektrik şebekeleri veri algılama, toplama, iletme, değerlendirme ve depolama işlemlerini gerektirir. Çok sayıda duyarga donanımlı cihazlar ile akıllı elektronik sistemler elektrik şebekelerinde çeşitli amaçlar için kullanılmaktadır. Bu cihazlardan alınan veriler önce veri toplama merkezlerinde toplanırlar daha sonra işlenmek ve değerlendirilmek üzere kontrol/ana merkezlere aktarılırlar. $\mathrm{Bu}$ nedenle, ak1llı şebekeler için tesis edilen iletişim ağları, bu veri yükünü ve trafiğini kaldıracak şekilde tasarlanmalıdırlar (Usta, 2013).

Akıllı şebekeler için yerel ağ veya alan üzerinde veri toplamada kullanılabilecek farklı haberleşme protokolleri (Bluetooth, WiFi, Zigbee vb.) bulunmaktadır. Bu haberleşme protokollerinden biri olan Zigbee, yakın zamanda akılllı şebekeler için düşük enerji tüketimi ve düşük maliyetli cihazların oluşturulmasında bir uygulama katmanı olarak tanımlanmıştır. $\mathrm{Bu}$ haberleşme protokolünün sağladığı avantajlar ile veri toplamada kullanılması, konu hakkındaki çalışmalarda incelenmiş olup, Tablo 1 üzerinde diğer haberleşme protokollerinden fark1 görülebilmektedir. (Sherin vd., 2014; Karasulu vd., 2009; Kıral, 2014; Zhang vd., 2012; Bonganay vd., 2014; Uğuz vd., 2013; Çetinkaya vd., 2015).

Yerel ağ üzerinden toplanan verilerin takip edilmesi ve bir veri bankasında saklanmasi gerekliliği oluşmaktadır. Bu tür işlemler için değişik metotlar olmasına rağmen açık kaynak kodlu modül veya yazılımların tercih 
Tablo 1. Kablosuz sensör ağlarının karşılaştırılması (Leccese vd., 2014)

\begin{tabular}{|c|c|c|c|}
\hline & ZIGBEE & WI-FI & BLUETOOTH \\
\hline IEEE Standartı & 802.15 .04 & $802.11 \mathrm{~b} / \mathrm{g}$ & 802.15 .01 \\
\hline Ana Uygulamaları & Kontrol & Genişband & Mobil Cihazlar \\
\hline Ağ Cihazlarının Sayısı & 65.000 'e kadar & 32 & 7 \\
\hline Bit İletim Oranı & $20-250 \mathrm{~kb} / \mathrm{s}$ & $11 / 54 \mathrm{Mb} / \mathrm{s}$ & $720 \mathrm{~kb} / \mathrm{s}$ \\
\hline İletişim Aralığı & $100 \mathrm{~m}$ & $100 \mathrm{~m}$ & $10 \mathrm{~m}$ \\
\hline Batarya Ömrü & $100-1000 \mathrm{Gün}$ & $1-5 \mathrm{Gün}$ & $1-7 \mathrm{Gün}$ \\
\hline
\end{tabular}

edildiği dikkat çekmektedir. Verilerin online olarak takip edilmesi için gateway modülü ile verilerin, online bir veri tabanına iletimi sağlanabilmektedir. Yapılan çalışmalar incelendiğinde fiziksel boyut ve maliyet değerleri dikkate alınarak Raspberry Pi kartının çalışmalarda gateway olarak kullanılabildiğini görmekteyiz. $\mathrm{Bu}$ kart sayesinde verilerin online bir veri tabanına iletilmesi sağlanabilmekte ve veriler görsel olarak MySQL veri yönetim sistemi ve PHP dili ile tasarlanmış internet sayfalarında takip edilebilmektedir (Faruque vd., 2016; Sheikh vd., 2014; Zhao vd., 2015; Sharma vd., 2015; Nikhade, 2015).

Çalışmanın amacı, bir ortam içerisinde her bir cihaz veya makine için elektriksel güç harcama verilerinin kablosuz olarak toplanabilmesini sağlayan bir kablosuz sensör ağı oluşturarak, bu sensör ağlarından toplanan verilerin, internet üzerine taşınmasını sağlayan gateway modülü ile online olarak bir alan adı üzerinden anlık ve geçmişe dair değerlerin grafiksel olarak gösterilmesini sağlayan bütünleşik bir sistem tasarlamaktır.

\section{Materyal ve Metot}

\section{a. Güç Ölçüm Devresi}

Yerel ağ üzerinden her bir cihazın veya makinenin harcadıkları elektriksel güç değerlerini elde etmek için, çektikleri elektriksel yük değerlerinin ölçülebileceği modüllerin oluşturulması gerekmektedir. $\mathrm{Bu}$ modüllerin her biri çalışmamız gereği ZigBee haberleşme protokolüne sahip bir kablosuz sensör düğümünü oluşturmalıdırlar. Bu sensör düğümlerinin oluşturduğu yap1 sayesinde kablosuz yerel ağ oluşturulmuş olacaktır. Bu yüzden uygun bir modül oluşturabilmek için uygun ekipman ve devre yapısına sahip olmak gerekmektedir.

Oluşturulan devre yapısında 3 ana birim yer almaktadır. Bunlar;

- PIC18F2550, devre üzerindeki matematiksel işlemler ve haberleşme trafiğini yönetmek için kullanılan ana denetleyici,

- XBee modülü, kablosuz veri iletimi için ZigBee haberleşme protokolünün mesh yapısını destekleyen kablosuz veri iletişim modülü,

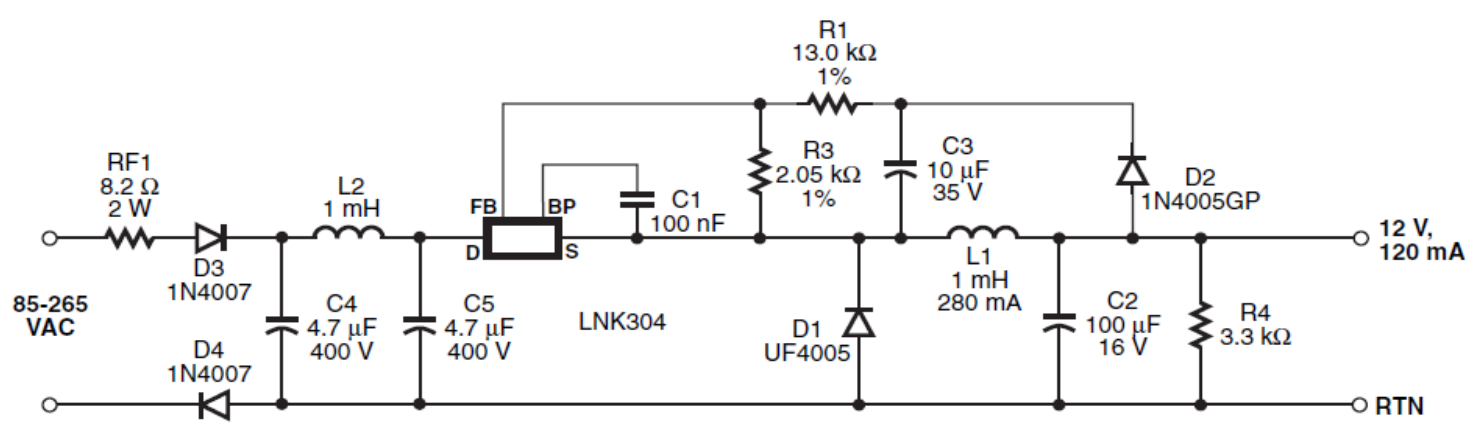

Şekil 1. 220V AC - 12V DC Çevrim Devresi (LNK304-LinkSwitch Datasheet) 
- CS5490 entegresi, RMS akım ve gerilim değerini ölçen entegre.

Devre üzerinde bulunan elemanların çalışması için gereken ana faktör güç kaynağ olmaktadır. Kullanılan elemanların besleme voltajları incelendiğinde devrenin $3.3 \mathrm{~V}$ ile beslenmesi gerektiği görülmektedir. $\mathrm{Bu}$ gerilim değerini sağlayabilmek için $220 \mathrm{~V} \mathrm{AC}$ değerini $3.3 \mathrm{~V}$ DC değerine çeviren bir dönüştürücü devre oluşturulmuştur.

Devre (Şekil 1) incelendiğinde çıkış geriliminim 12V DC olduğu görülmektedir. $\mathrm{Bu}$ değeri $3.3 \mathrm{~V}$ değerine indirgemek için LF33CV isimli voltaj regülatörü kullanılmıştır.

Bir hat üzerinden okunan gerilim ve akım değerleri ile hat üzerindeki harcanan güç değerleri, \%0.1' lik ölçüm hata oranına sahip CS5490 entegresi kullanılarak okunabilmektedir. CS5490, iki kanallı, güç tüketimi 13mW'ın altında, SOIC paket yapısında olan, UART seri portuna sahip enerji ölçüm entegresidir. Her iki kanal için 24 bitlik, 4. Dereceden Delta-Sigma analogdijital çeviricilere sahiptir (Şekil 2). Hesaplamalar, ayarlanabilir bir enerji darbesiyle veya UART seri iletişim portu ile entegre içerisindeki kaydedicilere doğrudan müdahale edilerek yapılabilmektedir. En önemli özelliklerinden bir tanesi, okuduğu gerilim ve akım değerlerini RMS (Root Mean Square, Karelerinin Ortalamasının Karekökü) olarak kullanıcıya iletebilmesidir. Bunun için gereken hesaplamaları kendi içerisinde yapabilmektedir.

CS5490 entegresi kendi içerisinde kaydedicilere (register) sahiptir. $\mathrm{Bu}$ kaydediciler okunan değerleri tutmak ve entegrenin kalibrasyonu için gereken alanları barındırmak için kullanılmaktadır. Çalışmamızda entegrenin kaydedicileri üzerinden değer okumak ve kalibrasyonunu yapabilmek için UART seri port üzerinden PIC18F2550 ile haberleşmesi sağlanmıştır. CS5490 entegresinin, elektriksel güç harcama verileri için ölçüm birimi olarak kullanıldığg, yapılan çalışmalarda gözlemlenmiştir (Elma vd., 2018; Bhaskar vd., 2013).

Okunan değerlerin kablosuz ağ içerisinde yer alabilmesi için bu değerleri RF sinyallerine dönüştüren XBee modülleri kullanılmıştır. Bu modüllerin ZigBee haberleşme protokolünün

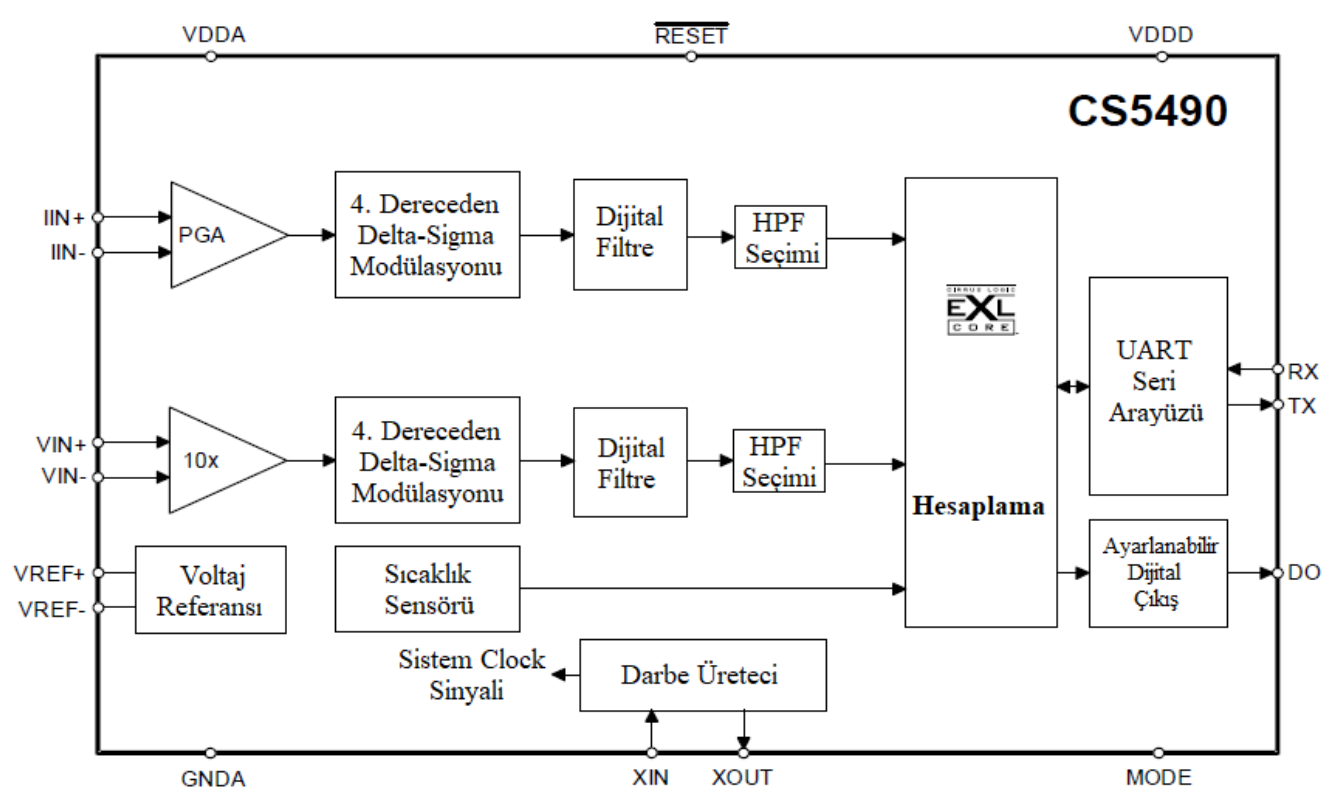

Şekil 2. CS5490 Blok Diyagramı (CS5490 Datasheet) 


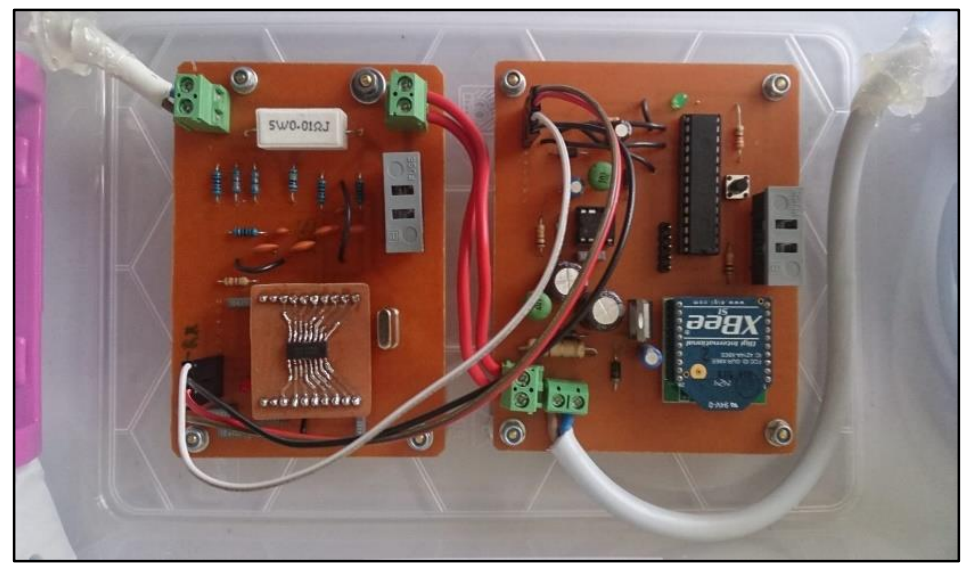

Şekil 3. Oluşturulan Elektriksel Güç Ölçüm Devresi

mesh yapısını destekleyen özellikleri sayesinde istenilen veri iletim yönteminde kullanılabilmeleri gerçekleştirilmiştir. XBee modüllerinin PIC18F2550 ile seri port üzerinden haberleşmesi sağlanmış ve iletim için gereken verileri denetleyici üzerinden alabilmiştir. Teorik olarak planlanan ve oluşturulan ölçüm modülünün $\mathrm{PCB}$ test düzeneği olarak gerçekleştirilmiş hali Şekil 3 üzerinde görülmektedir.

\section{b. Verilerin Grafiksel ve Sayısal Takibi}

Veriler, Zigbee mesh yapısı içinde koordinatör olarak görev yapan modül üzerinden toplanmaktadır. $\mathrm{Bu}$ koordinatör modül, verileri Raspberry Pi kartına iletmektedir. Raspberry Pi kartı, gateway olarak sistemde kullanıldığından, verileri internet ortamina iletmek üzere Python programlama dili ile programlanmıştır.
Toplanan verilerin işlenerek anlamlı hale getirilmesi ve bu verilerin internet üzerinden takip edilebilmesi için site tasarımı PHP (Hypertext Preprocessor) ile gerçekleştirilmiştir. PHP kullanılmasının nedeni, Linux, Microsoft Windows, Mac OS $X$ gibi büyük işletim sistemlerinde çalışabilmesi ve günümüzde yaygın biçimde kullanılan HTTP sunucularının (IIS, Apache) çoğunu desteklemesidir.

Verilerin bir internet sitesi üzerinde gösterilebilmesi için ilk olarak kayıt edilmeleri gerekmektedir. Bunun için verilerin düzenli olarak saklanması MySQL veri yönetim sistemi ile sağlanmıştır. $\mathrm{Bu}$ yazılımın kullanılmasındaki en önemli etken PHP ile olan kodlama uyumluluğu ve oluşturulan site içeriğinin rahatlıkla yönetilebilmesini sağlamasıdır (Şekil 4).

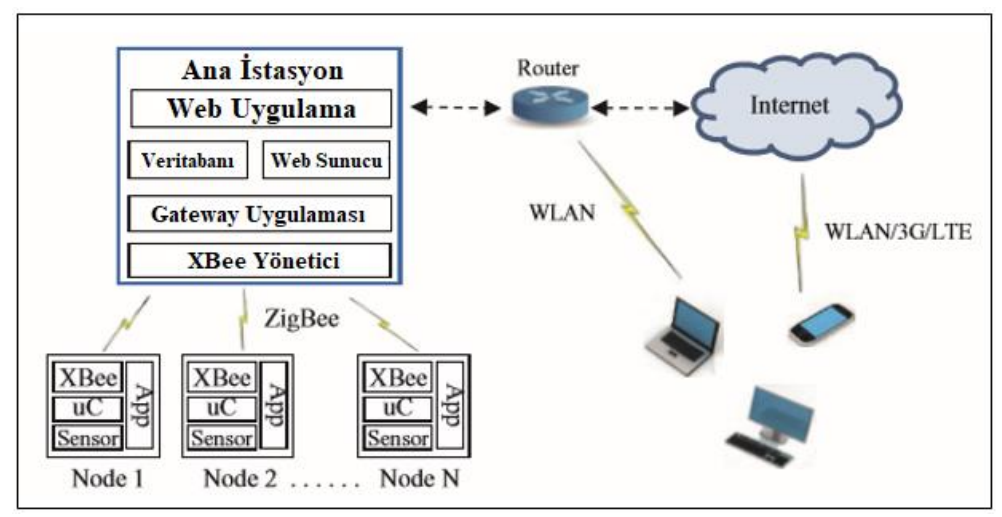

Şekil 4. Veri İletim Yöntemi (Ferdoush vd., 2014) 


\section{Bulgular}
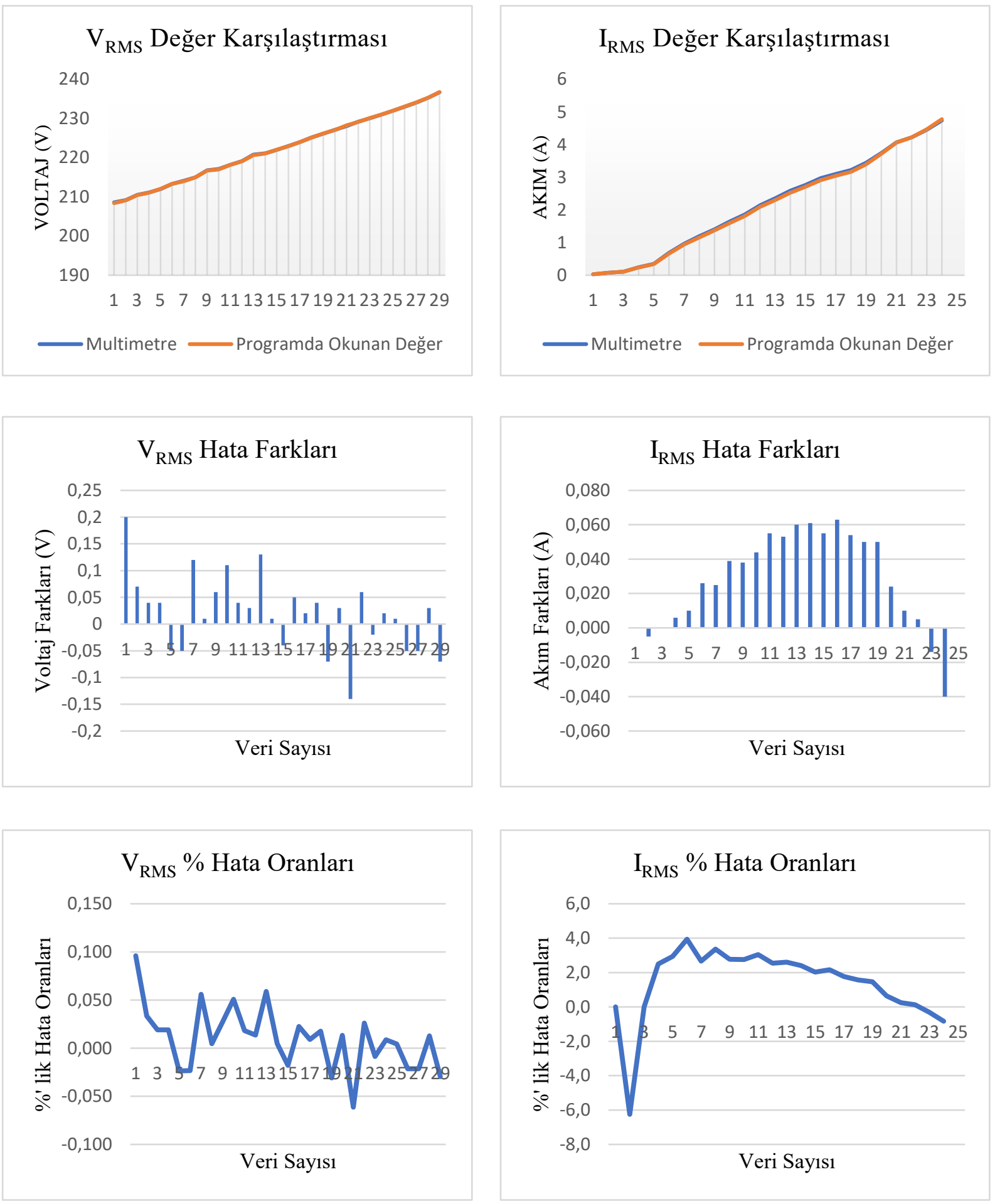

Şekil 5. Güç Ölçüm Devresinden ve FLUKE 179 Multimetresinden Okunan V VMS,

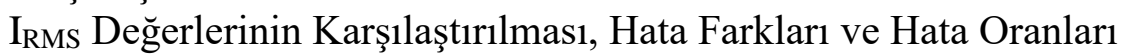


Şekil 5. incelendiğinde $V_{\text {RMS }}$ için, maksimum hata fark $0.2 \mathrm{~V}$, maksimum hata oranının ise $\% 0.1$ değerini geçmediğini görmekteyiz. $\mathrm{Bu}$ oran, kullanılan CS5490 entegresi için uygun gerilim hata oranı aralığındadır.

$\mathrm{I}_{\mathrm{RMS}}$ için maksimum hata farkının $65 \mathrm{~mA}$, maksimum hata oranının ise $\% 6$ olduğunu görmekteyiz. CS5490 entegresinin katalog bilgileri incelendiğinde \%6' lik hata oranının oldukça yüksek olduğu anlaşılmaktadır fakat buradaki yüzdelik değer 2. ölçümden kaynaklanan (80mA) 5mA' lik sapma değerinden meydana geldiği için dikkate alınmayabilir. Genel I $\mathrm{I}_{\mathrm{RMS}}$ sapma oranları incelendiğinde ise okunan değerlerin katalog bilgilerine göre \%0.1 değerini geçmemesi gerekmektedir ancak yapılan ölçümlerde \%4' e kadar sapmaların olabildiği görülmüştür. $\mathrm{Bu}$ durum güç ölçüm devresinden yanlış değerler okunmasına neden olacaktır. $\mathrm{Bu}$ konu hakkında yapılan çalışmalar incelendiğinde
CS5490 entegresinden okunan değerler hakkında genellikle doğruluk oranları ile ilgili detaylı bilgi verilmediğinden istenilen ölçüm değerlerinin okunabildiği varsayılmaktadır. $\mathrm{Bu}$ yüzden mikrodenetleyici için yazılan program tekrardan incelenmiş olup, CS5490 entegresinin örnekleme zamanına bağlı olarak kalibrasyonunun yapılması ve değerlerin bu zaman sonunda okunması gerektiği görülmüştür.

\section{Sonuç ve Tartışma}

Şekil 6. üzerinde verilerin iletimi için tasarlanan yöntemin istenilen şekilde çalışması ve çıktıların internet sitesi üzerinden takip edilebilmesi sağlanmıştır. Ek olarak T1T2-T3 zaman periyotlarına göre harcanan güç değerlerinin izlenebilmesi ve istenildiği takdirde bu zaman dilimlerine ait $\mathrm{kWh}$ cinsinden harcama maliyetlerinin de takip edilebilmesi sağlanmıştır.

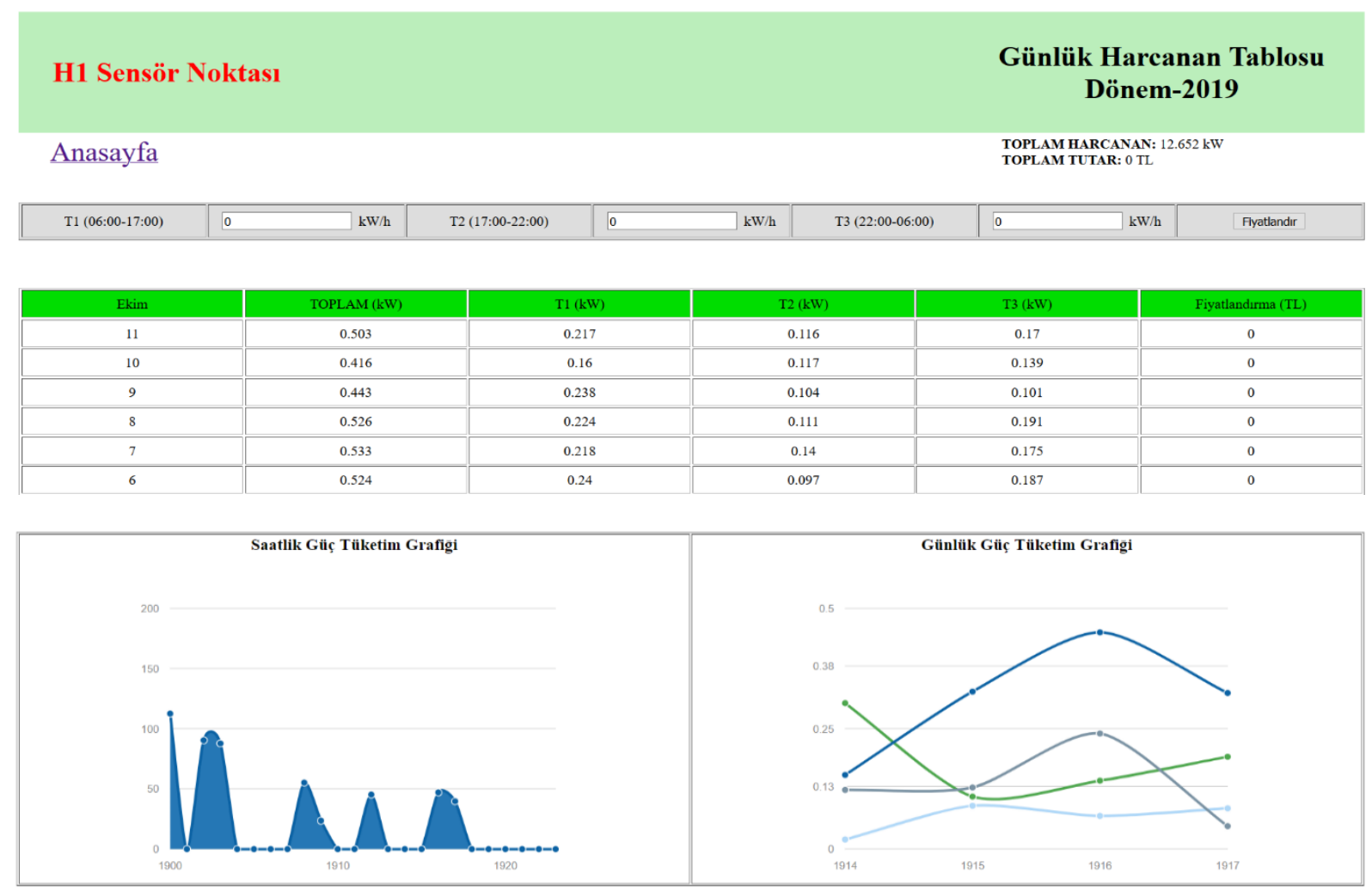

Şekil 6. Verilerin İnternet Üzerinden Sayısal ve Grafiksel Takibi İçin Tasarlanan Site 


\section{Kaynaklar}

Akcanca, M. A., Taşkın, S. 2013. "Akıllı Şebeke Uygulanabilirliği Açısından Türkiye Elektrik Enerji Sisteminin İncelenmesi", Akzlll Şebekeler ve Türkiye Elektrik Şebekesinin Geleceği Sempozyumu, TMMC. Elektrik Mühendisleri Odas1, Ankara, 131135 .

Akçin, M., Baykant B. A., Keleş, C., Karabiber, A., Kaygusuz, A. 2013. "Dağıtık Kontrol İle Akıllı Şebekelerde Geniş-A..... Yönetimi ve Geleceğe Dönük Projeksiyonlar", Sakarya Üniversitesi Fen Bilimleri Enstitüsü Dergisi, Cilt 17(3), 457470.

Bhaskar, C., Harikrishna, K. 2013. "Rogowski Coil for Current and OnTemperature Monitoring Overhead Transmission Lines", International Journal of Computer Applications, Vol. 82(2), 28-30.

Bonganay, A. C. D., Magno, J. _., Marcellana, A. G., Morante, J. M. E., Perez, N. G. 2014. "Automated Electric Meter Reading and Monitoring System Using ZigBee-Integrated Raspberry Pi Single Board Computer via Modbus", 2014 IEEE Students Conference on Electrical, Electronics and Computer Science, India, 1-6.

Çetinkaya, O., Akan, Ö. B. 2015. "A Zigh .. Based Reliable and Efficient Power Metering System for Energy Management and Controlling", 2015 International Conference on Computing, Networking and Communications (ICNC), Green Computii Networking and Communications Symposium, USA, 515-519.

Elma, O., Selamoğulları, U. S. 2018. "Gerilim Kontrol Tabanlı Ev Enerji Yönetim Sistemi İçin Bir Ak1llı Transformatör Uygulamas Gazi Üniversitesi Mühendislik Mimarlı Fakültesi Dergisi, 33(4), 1543-1556.

Faruque, M. A. A., Vatanparvar, K. 2016. "Energy Management-as-a-Service over Fog Computing Platform" IEEE Internet of Thir Journal, Vol. 3(2), 161-169.
Ferdoush, S., Xinrong, Li. 2014. "Wireless Sensor Network System Design Using Raspberry Pi and Arduino for Environmental Monitoring Applications." Procedia Computer Science, Vol. 34, 103-110.

Karasulu, B., Toker, L., Korukoğlu, S. 2009. "ZigBee-IEEE 802.15.4 Standart1 Temelli Kablosuz Algılayıcı Ağları" XIV. Türkiye'de Internet Konferansl-Inet-tr'09, İstanbul, 109116.

Kıral, G. E. 2014 "Akılllı Şebekelerde Enerji Yönetimi İçin Akıllı Priz Geliştirilmesi", Yüksek Lisans Tezi, Fen Bilimleri Enstitüsü, Yıldı Teknik Üniversitesi, Elektrik Mühendisliği Anabilim Dalı, İstanbul.

Leccese, F., Cagnetti, M., Trinca, D. 2014. "A Smart City Application: A Fully Controlled Street Lighting Isle Based on Raspberry-Pi Card, a ZigBee Sensor Network and WiMAX.", Sensors, 14, 24408-24424.

Nikhade, S. 2015. "Wireless Sensor Network System Using Raspberry Pi and Zigbee for Environmental Monitoring Applications", International Conference on Smart Technologies and Management for Computing, Communication, Controls, Energy and Materials (ICSTM), India, 418423.

Sharma, D. P., Baldeo, A., Philip, C. 2015. "Raspberry Pi based Smart Home for Deployment in the Smart Grid", International Journal of Computer Applications, Vol. 119(4), 6-10.

Sheikh, F., Li, X. 2014. "Wireless Sensor Network System Design Using Raspberry Pi and Arduino for Environmental Monitoring Applications", Procedia Computer Science, Vol. 34, 103-110.

Sherin, A., Li, X. 2014. "A Cost-Effective Wireless Sensor Network System for Indoor Air Quality Monitoring Applications.", Procedia Computer Science, Vol. 34, 165171.

Uğuz, S., Kılıç, B., Şişeci, M. 2013. “Akı1lı Ev Otomasyonu Sistemlerinde Zigbee Tabanl 1 Ağ Uygulamaları", III. Elektrik Tesisat Ulusal Kongresi Kapsaminda 6. Kontrol Otomasyon 
ve Yapı Elektronik Sistemleri Sempozyumu, İzmir.

Usta, Ö., Kahraman, Y. 2013. "Ak1ll1 Elektrik Şebekeleri ve Veri İletişimi”, Akull Şebekeler ve Türkiye Elektrik Şebekesinin Geleceği Seтроzуити, TMMOB Elektrik Mühendisleri Odası, Ankara.

Zafar, R., Mahmood, A., Razzaq, S., Ali, W., Naeem, U., Shehzad, K. 2018. "Prosumer Based Energy Management and Shared in Smart Grid", Renewable and Sustainable Energy Reviews, Vol. 82(1), 1675-1684.

Zhang, Y., Rong, Y., Nekovee, M., Xie, S., Liu, Y., Gjessing, S. 2012. "Cognitive Machine to Machine Communications: Visions and Potentials for The Smart Grid", IEEE Network, Vol. 26(3), 6-13.

Zhao, C. W., Jegatheesan, J., Loon, S. C. 2015. "Exploring IOT Application Using Raspberry Pi", International Journal of Computer Networks and Applications, Vol. 2(1), 27-34. 